\title{
Input Constraints and the Efficiency of Entry: Lessons from Cardiac Surgery
}

\section{Citation}

Cutler, David M., Robert S. Huckman, and Jonathan T. Kolstad. 2010. Input constraints and the efficiency of entry: lessons from cardiac surgery. American Economic Journal: Economic Policy 2(1): 51-76.

\section{Published Version}

doi:10.1257/pol.2.1.51

\section{Permanent link}

http://nrs.harvard.edu/urn-3:HUL.InstRepos:5344226

\section{Terms of Use}

This article was downloaded from Harvard University's DASH repository, and is made available under the terms and conditions applicable to Open Access Policy Articles, as set forth at http:// nrs.harvard.edu/urn-3:HUL.InstRepos:dash.current.terms-of-use\#OAP

\section{Share Your Story}

The Harvard community has made this article openly available.

Please share how this access benefits you. Submit a story.

\section{Accessibility}


NBER WORKING PAPER SERIES

\title{
INPUT CONSTRAINTS AND THE EFFICIENCY OF ENTRY: LESSONS FROM CARDIAC SURGERY
}

\author{
David M. Cutler \\ Robert S. Huckman \\ Jonathan T. Kolstad \\ Working Paper 15214 \\ http://www.nber.org/papers/w15214
}

\author{
NATIONAL BUREAU OF ECONOMIC RESEARCH \\ 1050 Massachusetts Avenue \\ Cambridge, MA 02138 \\ August 2009
}

We thank seminar participants at the American Society of Health Economists, Duke University, Harvard University, the International Health Economics Association, the National Bureau of Economic Research, the University of Illinois at Chicago, the University of Pennsylvania, and Washington University-St. Louis for helpful comments. We acknowledge financial support from the National Institute on Aging (Grant P01 AG005842) and the Harvard Business School Division of Research and Faculty Development. The data used in this analysis were obtained from the Pennsylvania Health Care Cost Containment Council (PHC4), which requests the following disclaimer: The Pennsylvania Health Care Cost Containment Council (PHC4) is an independent state agency responsible for addressing the problem of escalating health costs, ensuring the quality of health care, and increasing access to health care for all citizens regardless of ability to pay. PHC4 has provided data to this entity in an effort to further PHC4's mission of educating the public and containing health care costs in Pennsylvania. PHC4, its agents and staff, have made no representation, guarantee, or warranty, express or implied, that the data -- financial, patient, payor, and physician specific information -- provided to this entity, are error-free, or that the use of the data will avoid differences of opinion or interpretation. This analysis was not prepared by PHC4. This analysis was done by David M. Cutler, Robert S. Huckman, and Jonathan T. Kolstad. PHC4, its agents and staff, bear no responsibility or liability for the results of the analysis, which are solely the opinion of the authors. The views expressed herein also do not necessarily reflect the views of the National Bureau of Economic Research.

(C) 2009 by David M. Cutler, Robert S. Huckman, and Jonathan T. Kolstad. All rights reserved. Short sections of text, not to exceed two paragraphs, may be quoted without explicit permission provided that full credit, including (C) notice, is given to the source. 
Input Constraints and the Efficiency of Entry: Lessons from Cardiac Surgery

David M. Cutler, Robert S. Huckman, and Jonathan T. Kolstad

NBER Working Paper No. 15214

August 2009

JEL No. I10,I11,I18,L1,L15,L23,L5,L8

\section{$\underline{\text { ABSTRACT }}$}

Prior studies suggest that, with elastically supplied inputs, free entry may lead to an inefficiently high number of firms in equilibrium. Under input scarcity, however, the welfare loss from free entry is reduced. Further, free entry may increase use of high-quality inputs, as oligopolistic firms underuse these inputs when entry is constrained. We assess these predictions by examining how the 1996 repeal of certificate-of-need (CON) legislation in Pennsylvania affected the market for cardiac surgery in the state. We show that entry led to a redistribution of surgeries to higher-quality surgeons and that this entry was approximately welfare neutral.

David M. Cutler

Department of Economics

Harvard University

1875 Cambridge Street

Cambridge, MA 02138

and NBER

dcutler@harvard.edu

Robert S. Huckman

435 Morgan Hall

Harvard Business School

Boston, MA 02163

and NBER

rhuckman@hbs.edu
Jonathan T. Kolstad

University of Pennsylvania

108 Colonial Penn Center

3641 Locust Walk

Philadelphia, PA 19104-6218

jkolstad@wharton.upenn.eduu 
The classic welfare analysis of firm entry involves a tradeoff between the benefits of competition and losses from rent seeking. The benefits of competition are straightforward; the rent-seeking losses stem from the fact that part of an entrant's profit is generated by stealing business from incumbent firms. These transferred profits are not a social benefit, but the fixed outlays associated with entry represent a social cost. Under these conditions, Gregory Mankiw and Michael Whinston (1986) show that excessive entry is likely. This standard model, however, does not address a key feature of many industries: the inelastic supply of certain factors of production, such as labor or land. We consider the impact of such constrained inputs on the welfare economics of entry by studying hospital entry into the provision of coronary artery bypass graft (CABG) surgery. CABG represents a natural case study for two reasons: the supply of cardiac surgeons is roughly fixed in the short term and the quality of output is at least partially measurable.

With imperfectly supplied inputs, entry is less likely to be excessive than when inputs are more elastically supplied. A more subtle implication of constrained inputs relates to the level of quality at which firms will enter. In our setting, a surgeon may be a leader in the field or a novice, and when a hospital decides to enter the CABG market, it must decide which surgeons to employ. More generally, the decision about quality depends on the supply elasticity of factor inputs. Entry is likely to occur at high quality if high-quality labor is in relatively inelastic supply. In such a setting, oligopsonistic firms will ration use of high-quality workers prior to free entry, and new entrants will find such workers valuable. In contrast, entry will occur at lower quality if the supply of highquality labor is relatively elastic. 
To examine these implications empirically, we consider CABG entry by hospitals in Pennsylvania, which in 1996 eliminated its certificate of need (CON) policy that restricted entry by hospitals into expensive clinical programs, such as CABG. ${ }^{1}$ Repeal of CON was associated with significant hospital entry into CABG—-from 1996 to 2003 the number of hospitals providing this service in Pennsylvania increased from 43 to $63 .^{2}$ We rely on this growth to estimate the welfare effects of entry in this market.

The overall volume of CABG in Pennsylvania remained roughly flat for several years after CON repeal. We find that, as new programs entered the market, volume shifted from incumbent programs to entrants and from lower- to higher-quality surgeons. The repeal of CON in Pennsylvania thus appears to have had a salutary effect on the market for cardiac surgery by directing more volume to better doctors and increasing access to treatment. Offsetting this benefit are the fixed costs paid by new entrants of about \$13 million per program. On its own, the benefit of reduced mortality from the increased use of high-quality surgeons roughly offsets the fixed costs associated with free entry. Given our conservative assumptions and the fact that these estimates do not capture other gains from the repeal of CON (e.g., reductions in morbidity due to the reallocation of patients or reductions in administrative costs), our results suggest entry due to the repeal of CON was approximately welfare neutral.

\footnotetext{
${ }^{1}$ CON regulation has been studied in some detail (see Christopher J. Conover and Frank A. Sloan, 1998). The primary focus of this literature, however, has been on the cost implications of restricted entry. A smaller number of recent papers in both the health economics and medical literatures examine the impact of CON regulation on clinical quality (e.g., Vivian Ho, 2006; Verdi J. DiSesa et al., 2006; Robert H. Jones, 2006), as we do in this study.

${ }^{2}$ Our data include an additional hospital that entered the market in late 2003 performing a total of 31 surgeries by the end of 2003. Because entry occurred well after the repeal of CON—and we observe only a very small number of procedures from that hospital in our data - we exclude this facility from the remaining analysis.
} 
Our paper is structured as follows. Section I discusses entry decisions in the presence of fixed factors of production. Section II describes the cardiac surgery setting. Section III presents our results concerning the impact of repealing CON, Section IV estimates the welfare implications of this repeal, and Section V concludes.

\section{FIRM ENTRY IN MARKETS WITH CONSTRAINED INPUTS}

In general, firm entry into a market increases welfare by lowering prices (and thereby increasing volume) or increasing product variety (Avinash K. Dixit and Joseph E. Stiglitz, 1977; Spence, 1980; Roger W. Koenker and Martin K. Perry, 1981; Mankiw and Whinston, 1986). These gains, however, come at the social cost of redundant fixed investments in setting up additional firms (Mankiw and Whinston, 1986). In the standard model, a tradeoff thus exists between the benefits of competition and the losses from additional costs of entry.

In healthcare, where demand is uncertain and insured consumers tend not to face full prices, entry can have additional welfare costs. These losses come from people getting too many or too few services or changes in quality that cannot be observed due to asymmetric information (Kenneth Arrow, 1963; Martin Gaynor, 2006; Mark V. Pauly, 2004). ${ }^{3}$ We begin by examining the more standard effect of competition and return to moral hazard below.

The nature of competition in the input market affects the welfare costs of entry, and we explore these effects when input supply is not perfectly elastic. We adopt a simple model of monopolistic competition in the input market. We refer to a "wage" for a

\footnotetext{
${ }^{3}$ The combination of these factors can lead to firms competing in a "medical arms race" with excess services provided to cover fixed entry costs (Robinson and Luft, 1985).
} 
surgeon but note that compensation is more likely set by a bargain in which the hospital and surgeon agree to an appropriation of the rents from performing surgery. In the monopolistically competitive input market, supply elasticity effectively captures the market power held by the surgeon and hospital, respectively. ${ }^{4}$ Relying on this framework allows us to capture the basic predictions of a Nash bargaining solution while also considering the welfare impact of entry in the same model employed by Mankiw and Whinston (1986).

The first prediction is relatively straightforward. Suppose that surgeons are a scarce input, available in imperfectly elastic supply. Such input scarcity raises the cost of entry, thereby reducing the profits of new firms. The less elastic is labor supply, the smaller is the predicted entry associated with opening up markets. ${ }^{5}$

Less straightforward is the situation where inputs vary in quality, and the elasticity of input supply differs by quality. Quality effects are particularly relevant in a

\footnotetext{
${ }^{4}$ The particular nature of the bargain may alter the explicit predictions of the model. However, to the extent that the bargaining framework results in each party being paid a reservation wage, the equilibrium converges to the monopolistically competitive outcome. For example, Oliver Hart and Jean Tirole (1990) show that, under a reasonable set of assumptions, the Nash bargaining solution between upstream and downstream firms results in Cournot prices and quantities in the output market (even if the upstream party is a monopolist). This situation also resembles our setting in that the mark-up due to market power is declining in the number of downstream firms (Patrick Rey and Tirole, 2007).

${ }^{5}$ In monopolistic competition, where firms maximize profit subject to demand and input elasticities, the condition for the equilibrium number of firms is related to the familiar Lerner equation:

$L=\frac{P-M C}{P}=\alpha_{N}\left(-\frac{1}{\eta_{q}}+\frac{1}{\eta_{L}}\right)$, where $\alpha_{N}$ is a measure of per firm market share, $\eta_{q}$ is the elasticity of demand and $\eta_{L}$ is the labor supply elasticity. The term $\frac{1}{\eta_{L}}$ captures the decrease in the markup resulting from higher factor costs with inelastic labor supply. Because $\alpha_{N}$ is declining in $N$ by definition, the inclusion of $\frac{1}{\eta_{L}}$ causes $\frac{\partial L}{\partial N}$ to be larger in magnitude (i.e., more negative). That is, the mark up dissipates faster with entry when inputs are not perfectly supplied.
} 
setting such as health care, where the technical skill of labor is important. ${ }^{6}$ A firm seeking to produce at a given level of quality must hire labor with the requisite skills. The cost of achieving a given level of output quality is thus determined by the relative scarcity of the inputs required to produce at that level of quality

A variety of considerations suggest that high-quality surgeons will have less elastic labor supply than standard-quality surgeons. Surgery is a skill that takes time to produce; thus, training of high-quality surgeons cannot occur very rapidly. Further, by definition the country as a whole has fewer superstar surgeons than average surgeons. In any given area, the supply of standard-quality surgeons thus will be more elastic than the supply of high-quality surgeons.

The negotiation that determines the allocation of rents between surgeons and hospitals depends—on one side—on the relative strength of a hospital's threat to substitute between surgeons at a given level of quality and —on the other —on the countervailing threat of a surgeon transferring volume to a different hospital. In this way, changes in the number of hospitals on equilibrium quantities and wage offers will differentially impact high-quality and standard-quality surgeons. ${ }^{7}$

To see this more precisely, consider the equilibrium quality and quantity choices made by hospitals when entry is prohibited. If hospitals act as oligopsonists in the input market, they will demand standard-quality (i.e., "acceptable”) surgeons more than highquality surgeons. The reason is that the supply of high-quality surgeons is less elastic,

\footnotetext{
${ }^{6}$ For example, the average mortality rate for the worst-performing 20 percent of bypass surgeons in our sample in 1994-1995 was 2.5 times that of the top 20 percent.

${ }^{7}$ John Sutton (1991) argues that firms can make investments that limit the degree of subsequent entry. His theory of endogenous sunk costs focuses primarily on investments, such as those in R\&D or brands, that are difficult for new entrants to replicate. To the extent that our model hinges on firms capturing a scarce input (i.e., high-quality labor) as a limiting factor in subsequent entry, it can be seen as an application of Sutton's model. Specifically, one may consider the recruitment of high-quality labor to be akin to R\&D aimed at improving the quality of a firm's product.
} 
causing hospital profits to dissipate more rapidly by employing them. In the limit with only one high-quality surgeon, that surgeon would earn all of the rents associated with his or her superior quality.

The entry of new firms reduces the ability of any one firm to influence the input market by withholding capacity, as each firm accounts for a smaller share of total output. In short, entry moves the market from its equilibrium oligopsony quantity to a larger near-competitive quantity. This increase in quantity will be larger in markets that are further from the competitive equilibrium under restricted entry - that is, markets where labor supply is less elastic. To the extent that high-quality surgeons supply labor less elastically than standard-quality surgeons, we would thus expect to see a differentially larger increase in the use of high-quality surgeons under free entry.

\section{EMPIRICAL SETTING AND DATA}

\section{A. CABG Surgery}

CABG surgery was developed in the late 1960s and entered mainstream use in the United States during the 1970s. The procedure involves surgically isolating a section of vein (from the leg) or artery (from the chest) and grafting it to create a bypass of blockage in the coronary artery. In a traditional CABG, the patient is placed on a heartlung bypass machine, which performs the functions of the heart during the grafting process. Following the procedure, the patient remains in the hospital for several days to allow caregivers to monitor the recovery process.

The use of CABG grew substantially during the technology’s first three decades. Among the United States population age 50 or greater, the number of CABG procedures 
grew from a nationwide total of 15,000 in 1971 to a peak of 552,000 in 1997 before falling to 424,000 by 2003 (National Center for Health Statistics, 2006). This decline in CABG has been attributed to increased competition from less-invasive treatments, such as percutaneous transluminal coronary angioplasty (PTCA) (David M. Cutler and Robert S. Huckman, 2003). PTCA is a less intensive way of fixing coronary occlusions, but failure during the procedure can require emergency CABG surgery. As a result, many states, including Pennsylvania, require the presence of CABG back-up for the performance of PTCA. ${ }^{8}$ Because PTCA is less intensive but still well reimbursed, its use spread over the 1990s and early 2000s. Thus some of the hospitals in our sample may have entered the CABG market with the primary aim of providing CABG itself while others may have done so with the primary aim of developing a strong PTCA program. We exploit this difference in entry motives as a robustness check later in our analysis.

CABG is an expensive procedure to provide, and the fixed costs of setting up a CABG facility are significant. Huckman (2006) finds the average fixed cost to establish a CABG program in New York State to be $\$ 14$ million. Further, Jamie Robinson et al. (2001) present reported setup costs of \$13.4 and \$12 million for two programs entering the Pennsylvania market in 2000. To put such an investment in perspective, we note that the average net income between 1996 and 2005 for hospitals entering the CABG market in Pennsylvania was $\$ 3.5$ million. ${ }^{9}$ In addition, the ongoing costs of a CABG program are significant, as hospitals offering the procedure typically employ a staff of nurses, perfusionists, and other technicians dedicated to cardiac surgery.

\footnotetext{
${ }^{8}$ In certain "low-risk" cases, PTCA may be conducted at a Pennsylvania hospital without CABG back-up. Nevertheless, the majority of PTCA cases occurring during our sample period would have required the presence of CABG at the hospital.

${ }_{9}^{9}$ Authors calculation using data from the Medicare Cost Reports 1996-2005.
} 
Despite its high cost, CABG is very profitable for hospitals. Roughly half of CABG patients are covered by Medicare, which pays relatively generously. Most of the remainder is privately insured. Further, a large number of people have coronary artery disease, so resources rarely sit idle. It is generally believed that, along with orthopedics and oncology, cardiac care accounts for the bulk of many hospitals’ profit. Thus, the impact of CON regulation on CABG surgery has important implications for overall hospital profitability.

\section{B. The Hospital-Surgeon Relationship}

Our model assumes that firms choose the quality of the employees they hire. With few exceptions, however, hospitals tend not to employ surgeons. Rather, they provide them with surgical privileges and access to facilities, such as operating rooms. Still a hospital may provide a surgeon with various non-pecuniary benefits that may influence the degree to which the surgeon performs procedures at that facility. For example, one way for a hospital to lure a physician is through preferred scheduling: the physician might be promised his or her choice of operating rooms and a dedicated time to use the room. The quantity and composition of the surgeon's clinical support staff, such as nurses and anesthesiologists, represents another means by which hospitals may attract surgeons. In addition, there may be intangible benefits such as preferred access to parking, office space, and administrative support. Effectively, the hospital and physician enter an at-least-implicit contract that specifies how the joint benefits of surgery are to be split, without any direct money changing hands between the two parties. As such, we think of this relationship as akin to employment, even without a direct monetary 
transaction. In this case, the "wage” paid by the hospital is reflected in the value of the various benefits conveyed to the surgeon.

\section{CABG and CON Regulation in Pennsylvania}

With encouragement from the federal government, individual states instituted CON regulations for hospitals during the 1970s. These regulations required state approval before hospitals could invest in costly technologies, such as cardiac surgery. CON was instituted as a reaction to concerns that competition between hospitals would lead to a "medical arms race” (James Robinson and Harold Luft, 1985) characterized by excessive service provision and increased cost. During the 1980s, a push toward deregulation reduced federal funding for CON programs, and states responded by dismantling or scaling back these regulations. On December 18, 1996, Pennsylvania repealed its CON law, effectively allowing free entry into a broad range of hospital services, including cardiac surgery.

At the time Pennsylvania repealed its CON law, 43 hospitals were licensed to provide CABG surgery in the state. This figure represented 16 percent of all acute-care hospitals in the state and 33 percent of all acute-care hospitals with 200 or more bedsthe threshold hospital size that is often assumed necessary to support a bypass program. Following the repeal of CON, entry into CABG was swift, as illustrated in Figure 1. Four programs entered in each of the years 1997 and 1998, and there were 23 total entrants by 2003. In 2000, post-CON entrants accounted for 10 percent of Pennsylvania’s total CABG volume. This figure grew to 20 percent by 2003. All 
together, there was a 46 percent net increase in the number of CABG programs in the state between 1996 and 2003. ${ }^{10}$

To determine how much of the above growth was due to the repeal of CON, Figure 2 presents the total number of CABG programs in Pennsylvania, New York, and New Jersey for the period from 1995 to 2003. Because New York and New Jersey maintained CON regulation throughout the study period, we use them as controls for the rate of growth in new CABG programs that would have occurred between 1995 and 2003 under regulated entry. Based on these controls, the repeal of CON led to the entry of between 10 and 16 of the 23 new CABG programs in Pennsylvania. ${ }^{11}$

A majority of hospitals that entered the CABG market after the repeal of CON were in the suburbs of major cities. Figure 3 plots incumbent and entrant programs on a map of Pennsylvania. Thirteen of the 23 entrants were in the suburbs of either Philadelphia or Pittsburgh. The remaining new programs were distributed throughout the state but tended to be located in medium-sized cities where an incumbent program had a virtual monopoly on CABG surgery prior to the repeal of CON. For example, both Johnstown and Altoona had one incumbent program each before 1996, and each faced one entrant following CON repeal. The Wilkes-Barre and Scranton area moved from two incumbent programs - one in each town — to a total of five programs. Some areas of the state, particularly the less-densely-populated northern interior, had few or no new programs.

\footnotetext{
${ }^{10}$ Between 1996 and 2003, three existing CABG programs exited the Pennsylvania market.

${ }^{11}$ We return to this estimate later when computing the welfare impact of the repeal of CON in Pennsylvania. We bound the cost in the welfare calculations between the fixed cost associated with the 20 new entrants (without controlling for New Jersey and New York) and the lower bound of 10 new entrants attributable to the policy change including controls from nearby states.
} 
Table 1 presents information on the size of new programs. On average, entrant programs are smaller than incumbents in terms of both total procedures and procedures per surgeon (160 procedures per year over the 2000-2003 period compared to 349 for incumbent programs). The relatively low volumes at entrant programs are not surprising given the time required for a new program to reach an "equilibrium” level of volume. For example, the three hospitals that entered the market in 1997 averaged 174 total surgeries in their first year of operation. By 2003, however, those same programs performed an average of 305 surgeries (relative to the 2003 average of 296 procedures per incumbent program) despite a decline in the statewide CABG volume between 1997 and 2003.

Many new programs aimed to establish themselves by contracting with surgeons who were already licensed in Pennsylvania and practicing at incumbent hospitals. Of the 225 surgeons performing at least one CABG procedure in Pennsylvania in the years 2000 through 2003, ${ }^{12} 122$ split their time across hospitals. Over half of the surgeons performing CABG surgery at entrant hospitals during the 2000-2003 period worked at a different institution under $\mathrm{CON}$; the remainder were new to the market.

Despite the entry of new surgeons, the net supply of surgeons did not change much during the study period. Between 1994 and 2004, there was a net increase of only 10 physicians, or 5 percent, ${ }^{13}$ despite the addition of many new programs.

\section{Data}

\footnotetext{
12 This figure excludes surgeons who performed surgeries only in 2001, as Pennsylvania did not make data on CABG procedures available for that year.

${ }^{13}$ Entry and exit are defined by the year of licensure in the state of Pennsylvania. Exit year is determined by the last available year that a surgeon was licensed to practice if a license was not renewed. Entry is the first year a surgeon was licensed to practice in the state.
} 
The primary source of data for our analysis is the Pennsylvania Health Care Cost Containment Council (PHC4), which has collected patient-level records for every individual receiving CABG at a hospital in Pennsylvania in 1994, 1995, 2000, 2002, and 2003. ${ }^{14}$ These data cover 89,406 procedures performed by 303 physicians at 67 hospitals. The PHC4 data identifies both the surgeon and hospital associated with each procedure. In addition, it provides a wide range of patient-level covariates such as age, gender, and several clinical measures of illness severity.

For some descriptive analyses, we use another PHC4 database that reports the total number of CABG patients over the entire period from 1993 to 2003. These data, however, are from standard discharge abstracts and, as such, do not include the same patient-level clinical information that is found in the first database described above. In addition, these latter data do not have the validated surgeon identifiers that are present in the former dataset. Finally, we use data from the Medicare Cost Reports for the period from 1993 to 2003 to examine the profitability of various categories of Pennsylvania hospitals around the repeal of CON.

\section{E. Measuring Provider Quality}

We distinguish high-quality from standard-quality surgeons using data on the risk-adjusted, in-hospital mortality of their CABG patients. To adjust binary mortality outcomes for patient severity, we estimate the following logistic regression:

$$
\ln \left(\frac{\operatorname{mort}_{i, s, h}}{1-\operatorname{mort}_{i, s, h}}\right)=\alpha_{0}+\alpha_{1} \cdot X_{i}+\varepsilon_{i, s, h}
$$

\footnotetext{
${ }^{14}$ These data are not available for the years 1996-1999 and 2001.
} 
where $i$ indexes patients, $s$ surgeons, and $h$ hospitals. The indicator mort $_{i, s, h}$, equals one if patient $i$ died in the hospital and zero otherwise. $X_{i}$ is a matrix of covariates that includes controls for several patient characteristics and existing clinical conditions that could affect a patient's underlying probability of dying in the hospital. ${ }^{15}$ We calculate the riskadjusted mortality rate $\left(R A M R_{s, h}\right)$ for each surgeon-hospital pair as:

$$
R A M R_{s, h}=\left(O M R_{s, h} / E M R_{s, h}\right) * O M R_{P A}
$$

where $O M R_{s, h}$ is the observed mortality rate for surgeon $s$ at hospital $h$, and $E M R_{s, h}$ is the expected mortality rate - the average predicted probability of mortality from (1) — for the same surgeon-hospital pair. The final term, $O M R_{P A}$ is the average observed mortality rate for the entire state over the sample period; this multiplication normalizes risk-adjusted mortality to the statewide average.

\section{RESULTS}

We report our results in four parts. First, we look at the impact of entry on the volume of cases and profit for entrant and incumbent hospitals. Second, we consider how market share shifts among surgeons of different quality levels following entry. Third, we examine whether these changes in volume have spillover effects - positive or negative due to scale effects at the level of the hospital or surgeon. Finally, we look at the impact of entry on the distances patients travel for care.

\section{A. Changes in Quantity and Profit}

\footnotetext{
${ }^{15}$ Examples of the variables included in $X_{i}$ are patient age, gender, complicated hypertension, heart failure, heart attack, kidney failure, and cardiogenic shock. A full list of the covariates included in this regression, as well as the resulting coefficient estimates, can be found in various PHC4 publications. For instance, the covariates and results for the 1994 and 1995 data can be found in Pennsylvania Health Care Cost Containment Council (1998).
} 
Standard models predict that free entry will lower prices and raise volume, thereby increasing consumer surplus. In health care, however, the situation is somewhat more complex. Because consumers often are not well informed about their needs for particular services and are insured for much of the cost, it is not obvious that increased quantities of care are welfare enhancing. Indeed, many models of health care predict overconsumption in equilibrium (Arrow, 1963; Joseph P. Newhouse, 1970; Richard Zeckhauser, 1970), with greater service provision potentially reducing welfare. ${ }^{16}$ Determining the welfare impact of entry-related changes in volume thus requires empirical analysis.

Figure 4 shows per capita CABG volume in Pennsylvania between 1990 and 2003, as well as similar figures for New York and New Jersey—nearby states where CON regulation remained in place throughout the sample period. Though Pennsylvania provides significantly more CABG procedures per capita than either of the two control states, this relative difference does not change following the repeal of CON. In all three states, volume per capita increases in the early to mid-1990s and then declines, consistent with the national trend. Regression analysis confirms the impression from the figure. Relating CABG volume to a post-1996 indicator, state indicator variables, and a post1996 Pennsylvania-specific indicator yields a coefficient on the differential impact in Pennsylvania after 1996 of -417 (standard error $=2,234$ ). ${ }^{17}$ In addition to being statistically insignificant, the estimated value of this coefficient is actually negative suggesting, if anything, a slightly greater decline in total CABG volume following the repeal of CON.

\footnotetext{
${ }^{16}$ In fact, this argument is commonly offered as a reason for the institution of CON regulation.

${ }^{17}$ Our results are similar when the denominator of the CABG rate is limited to population age 45 and older.
} 
In addition to analyzing the effect of entry across states, we use variation in the timing and extent of entry across markets within Pennsylvania to estimate the effect of entry on the volume of CABG procedures at incumbent hospitals. We define markets using the hospital referral regions (HRRs) developed by John Wennberg et al. (1999) groups of zip codes in which residents travel to roughly the same hospitals for acute care. ${ }^{18}$ Wennberg et al. (1999) group Pennsylvania into 15 HRRs. We form semi-annual CABG volumes for incumbent and entrant hospitals and estimate longitudinal models for incumbent volume as a function of market fixed effects, year fixed effects, and entrant volume in the preceding six months. The results suggest that each additional surgery at an entrant program is associated with a reduction of 1.72 (standard error $=0.14$ ) surgeries at incumbent hospitals in the same HRR. This coefficient is significantly different not only from zero but also from one, suggesting that incumbent hospitals may substitute angioplasty for CABG in markets where entry is more prevalent. Taken together, the evidence both across states and within Pennsylvania suggests no increase in overall CABG utilization in conjunction with free entry. ${ }^{19}$

The complement to volume is price. Our data do not include information on prices paid to hospitals, as negotiated rates are proprietary. Nevertheless, some things are known. Fifty-four percent of the procedures in our data are performed on patients covered by Medicare. As a result of Medicare’s administered pricing system—with reimbursement depending on the diagnosis of the patient, the teaching status of the hospital, local wage rates, and the level of low-income patients the hospital serves-

\footnotetext{
${ }^{18}$ Specifically, the areas are defined by the hospitals visited for cardiac care by 80 percent of Medicare beneficiaries in that zip code (Wennberg et al.1999).

${ }^{19}$ These results are consistent with Steven T. Berry and Joel Waldfogel's (1999) study of free entry in radio broadcasting in which roughly eighty percent of new entry leads to the transfer of customers between firms without expanding demand.
} 
Medicare prices are not a direct choice variable for a hospital. Further, prices for patients with private insurance tend to vary with Medicare rates, making most hospitals pricetakers, at least in the short term. ${ }^{20}$

With no change in overall quantity but a shift of volume to new entrants, the short-run allocation of profits thus moves away from incumbent hospitals and toward entrants. Ordinarily, shifting profits is not a policy concern, as all profits count equally in social welfare calculations. This assumption may not be true in health care, however, where private firms provide varying levels of public goods. Most hospitals—at least notfor-profit hospitals—have an explicit goal of subsidizing less-profitable care with the returns from treating more-profitable patients. If incumbent $\mathrm{CABG}$ providers accounted for a disproportionately large share of the provision of public goods, free entry could thus result in welfare losses from the redistribution of rents.

A common measure of less-remunerative care is the share of uninsured people seen at a given hospital. Unfortunately, we are not able to obtain this information for the institutions in our sample. Nevertheless, the level of Medicaid patients at a hospital is likely to be correlated with its level of uninsured patients. Thus, we examine how incumbent and entrant hospitals compare in terms of Medicaid admissions. We find that incumbent CABG hospitals have a larger proportion of Medicaid patients (across all diagnoses) than eventual CABG entrants. In 1994-1995, 15 percent of admissions at incumbent hospitals were insured by Medicaid, compared to 10 percent at eventual

\footnotetext{
${ }^{20}$ Chernew et al. (2002) find evidence of variation in the profitability of CABG surgery across payer types. They also find that competition reduces the profitability of CABG performed on managed care patients. We cannot investigate these effects directly without price data. We note, however, that our hospital-level profit analysis (below) addresses the welfare impact of changes in prices and payer mix to the extent they affect overall hospital profit.
} 
CABG entrants (p-value for difference $<0.01$ ) and 16 percent for those hospitals that never introduced CABG (p-value for difference $=0.54$ ).

Of course, hospital operations are not static, and these firms can react to a loss of profitable volume in many ways. For example, salaries might be lowered or services cut. To examine the impact of CON repeal on overall profitability, we consider the long-run impact of entry on profits. Hospitals are required to file cost reports with Medicare that list net patient revenues and operating expenses, from which we derive operating margins (i.e., operating income divided by net patient revenues).

We present data on trends in hospital profits, but note an obvious caveat: CABG is but one service offered by these hospitals, and overall profitability depends on the total portfolio of services provided by an institution. Still, two features argue for the relevance of this analysis. First, cardiac care is a large part of hospital profits, as noted earlier. Second, with the lessons learned from studying CABG may inform a hospital’s understanding of markets for similarly intensive services.

Figure 5 presents the time series of operating margins for incumbent and entrant hospitals, as well as other Pennsylvania hospitals that never entered the CABG market. All hospitals that eventually developed a cardiac program, either incumbents or entrants, are more profitable than those that never entered the market. Margins for incumbent hospitals were negative in much of the late 1990s—-the period immediately following CON repeal. However, these institutions regained profitability by 2002 and were, in fact, the most profitable hospitals by the end of the observation period. ${ }^{21}$ The specific steps

\footnotetext{
${ }^{21}$ To examine the significance of these changes, we ran a regression of operating margin for incumbent hospitals against the share of new entrants in the incumbent's hospitals HRR, a time trend, and hospital fixed effects. We found no significant effect of entry; the coefficient on entry share is negative but insignificant. The same was true for the profitability of entrants.
} 
incumbent hospitals took to regain profitability cannot be observed in our data, but the results suggest that, overall, these hospitals were not put in a precarious position by the elimination of CON.

\section{B. Changes in Quality from Redistribution of Inputs}

Our earlier theoretical discussion posits that free entry may increase the demand for relatively inelastic factors - in this case, high-quality surgeons. To evaluate the direct effect of entry on the input decisions of firms, we rely on variation in the level of entry across markets (i.e. HRRs) in Pennsylvania following the repeal of CON. We estimate the following specification:

$$
\begin{aligned}
& \text { surgshare }_{s, j, t}=\beta_{0}+\beta_{1} \text { entrantshare }_{-} \text {group }_{j, t}+\beta_{2} \text { highqual }_{s} * \text { entrantshare_group }_{j, t} \\
& +\beta_{3} \text { newdoc }_{s} * \text { entrantshare_group } \\
& j, t,
\end{aligned}
$$

We define surgshare $_{s, j, t}$ as the share held by surgeon $s$ in market $j$ in quarter $t$. We relate this variable to entrantshare_group $j_{j, t}$, a vector of indicators for whether the share of CABG procedures in market $j$ occurring at entrant hospitals is in the following categories: $1-10 \%, 11-20 \%$, or above $20 \%$; ighqual $_{\text {, }}$ an indicator for whether surgeon $s$ is a high-quality surgeon; ${ }^{22}$ and $n e w d o c_{s}$, an indicator for surgeons who entered the Pennsylvania market after CON repeal and, as a result, could not be distinguished by hospitals as being either standard- or high-quality in the period before CON repeal. We also interact entrantshare_group $p_{j, t}$ with both highqual and newdoc $s$. The coefficients on these interactions capture the differential share changes following entry for high-quality and new surgeons, respectively, compared to standard-quality surgeons.

\footnotetext{
${ }^{22}$ We discuss our definitions of high- and standard-quality surgeons later in the manuscript.
} 
We note that our specification of the entrant share variable enables us to capture a potential non-linear relationship between entry and the demand for particular categories of surgeons. Our theory suggests such non-linearity may exist, as the marginal effect of entry on oligopsony power in the market is declining in the number of firms. ${ }^{23}$

We define highqual $_{s}$ in four ways. Our base estimates define highqual $_{s}$ as the top 10 percent of surgeons with at least 50 operations in the CON period (1994-95). All other surgeons who performed at least one procedure in Pennsylvania in 1994-95 are considered standard-quality surgeons and represent the excluded category in our analysis. In subsequent estimates, we define ighqual $_{s}$ as the top 20, 30, and 40 percent of surgeons, respectively, using a similar methodology. As noted above, surgeons entering the Pennsylvania market after CON repeal are not eligible for the ighqual $_{s}$ category and instead are included in the newdoc $c_{s}$ category.

Control variables in (3) include fixed effects for quarter $\left(\alpha_{t}\right)$ and surgeon-market pairs $\left(I_{s, j}\right)$. Our model predicts $\beta_{2}>0$ : when more firms enter a market, the share of surgeries performed by high-quality surgeons should rise relative to the share held by standard-quality surgeons.

Estimates of $\beta_{1}$ are negative and precisely estimated over all ranges of entrant share in Column 1 of Table 2. The sign of these coefficients suggests that gains in share by entrant hospitals are associated with reductions in share for standard-quality surgeons.

\footnotetext{
${ }^{23}$ General models of entry with imperfect competition also predict a non-linear relationship between entry and competition. Timothy F. Bresnahan and Peter C. Reiss (1991) study entry empirically and find most of the competitive effect comes from the second and third entrants, with diminishing impact on market conduct beyond that level. Jean M. Abraham et al. (forthcoming) also find a non-linear effect of entry on competition in hospital markets.
} 
As we relax the definition of a high-quality surgeon in Columns 2 and 3, this relationship remains negative and significant for entrant shares between one and 10 percent.

Consistent with our predictions, the estimates of the $\beta_{2}$ coefficients are positive and significant in Column 1 for markets with up to 20 percent share held by entrant hospitals. The magnitude of the coefficients suggests that increasing entrant share beyond zero and up to 10 percent is associated with an increase of 2.6 percentage points for the average high-quality surgeon relative to the impact for the average standardquality surgeon. For entrants holding between 10 and 20 percent share, this increase is 2.1 percentage points greater than the 1.2 percentage point decline for standard-quality surgeons. The magnitude of these effects is economically significant. The average highquality surgeon (based on the top 10 percent definition) had an average market share of 4.9 percent between 2000 and 2003. The reallocation associated with entry is thus equivalent to a 53 percent increase (relative to the mean) in share for high-quality surgeons in markets with positive entrant share less than 10 percent and a 44 percent increase for the same surgeons in markets with entrant share between 10 and 20 percent. In Columns 2 and 3, the coefficient estimates for $\beta_{2}$ are positive for entrant shares between one and 10 percent, though the point estimates are smaller and significant at only the $10 \%$ level.

The effect of new entry on reallocation to high-quality surgeons falls off in all specifications as entrant market share grows beyond either 10 or 20 percent. This tapering suggests entry up to that point may be sufficient to push demand for high-quality surgeons from its regulated level to the competitive equilibrium. Indeed, above these threshold entrant shares, additional share seems to go to surgeons who are new to the 
Pennsylvania market, as shown by the positive and relatively large (though statistically insignificant) $\beta_{3}$ coefficients for entrant shares above 10 percent. Finally, we note that both the magnitude and significance of the relative share increase for high-quality surgeons declines as we move from the most-restrictive definition of a high-quality surgeon (i.e., top 10 percent in Column 1) to the least restrictive (i.e., top 40 percent in Column 4). This tapering supports our contention that the top surgeons are in relatively high demand following entry.

Our analysis to this point has treated all entrants as similar. As noted earlier, however, this assumption may not be appropriate, as some hospitals may enter the CABG market because they want to do a significant number of CABG surgeries while others may enter primarily as backup for angioplasty (i.e., PTCA) services. Hospitals entering the CABG market primarily as backup for PTCA may place less of a premium on a highquality CABG surgeon and, in turn, may be more likely to contract with standard-quality surgeons.

As a robustness check, we test for this distinction by measuring the degree to which each entrant hospital is "focused" on either CABG or PTCA. Our measure of focus is CABG's share of all revascularization procedures (i.e., CABG plus PTCA) at a hospital after it enters the CABG market. For each entrant, we compare the actual value of this CABG share measure to its predicted value based on a regression for all entrants, controlling for calendar time and years since entry. Hospitals with higher-than-predicted 
CABG shares are classified as $C A B G$ focused while those with lower-than-predicted shares are classified as PTCA focused. ${ }^{24}$

There are two potential concerns with this measure. First, ex post CABG volume may be affected by quality after entry. Second, entering hospitals may not reach their “equilibrium” focus immediately. We attempt to minimize both concerns by computing a hospital's CABG share during its second year in the CABG market. This timing is long enough to reduce the noise in CABG share due the initial ramp up of new programs but short enough to minimize a program's ability to adjust volume endogenously. Further, even a noisy approximation of CABG focus provides a useful measure to test the robustness of our estimates for the overall effects of entry from equation (3). Using this methodology, 13 of the 23 entrants were CABG focused.

After determining each entrant's focus, we estimate the following model:

$$
\begin{aligned}
& \text { surgshare }_{s, j, t}=\beta_{0}+\beta_{1} \text { CABGentrantshare_group } p_{j, t}+\beta_{2} \text { highqual }_{s}^{*} \text { CABGentrantshare_group } p_{j, t} \\
& +\beta_{3} \text { newdoc }_{s} * \text { CABGentrantshare_group }{ }_{j, t}+\beta_{4} \text { PTCAentrantshare }_{-} \text {group }_{j, t} \\
& +\beta_{5} \text { highqual }_{s} * \text { PTCAentrantshare__roup }{ }_{j, t}+\beta_{6} \text { newdoc }_{s} * \text { PTCAentrantshare_group }{ }_{j, t} \\
& +\alpha_{t}+I_{s, j}+\varepsilon_{s, j, t}
\end{aligned}
$$

where CABGentrantshare_group $p_{j, t}$ and PTCAentrantshare_group $j_{j, t}$ are separate vectors of entrant share indicators—analogous to entrantshare_group $p_{j, t}$ in (1)—for CABG-focused and PTCA-focused entrants, respectively. Our theory suggests that CABG-focused entrants should be more likely than PTCA-focused entrants to view CABG surgeons as differentiated inputs. As such, our base results should be strongest among CABG-focused entrants, suggesting that we should expect $\beta_{2}>0$ and $\beta_{2}>\beta_{5}$.

\footnotetext{
${ }^{24}$ Formally, we regress the share of cardiac procedures (i.e., CABG plus PTCA) that were CABGs at hospital $h$ in quarter $t$ on the number of years since hospital $h$ entered the CABG market and indicators for calendar quarter.
} 
Table 3 illustrates that the effect of entry by PTCA-focused hospitals has no differential effect on the shares of surgeries held by high-quality or new surgeons ( $\beta_{5}$ and $\beta_{6}$, like $\beta_{4}$, are small and statistically insignificant). This is true over the full range of definitions for high-quality surgeons. In contrast, entry by CABG-focused hospitals leads to a statistically significant reallocation of surgeries toward top surgeons. Initial entry (i.e., up to 10 percent of the market held by CABG-focused entrants) leads to an average increase of 2.7 percentage points in market share for high quality surgeons relative to the average effect for standard quality surgeons. These effects continue to be positive and significant with subsequent entry. Entry resulting in 10 to 20 percent market share for CABG-focused entrants results in a 2.0 percentage point increase in share for highquality relative to standard-quality surgeons; entrant share in excess of 20 percent leads to a relative increase of 3.1 percentage points for high-quality surgeons. ${ }^{25}$

\section{Changes in Quality from Volume-Outcome Effects}

The redistribution of cases from standard- to high-quality surgeons may have a secondary effect on quality due to within-surgeon changes in volume that could themselves induce changes in quality. This effect, commonly referred to as the volumeoutcome relationship, is based on the premise that higher volume is associated with better surgical outcomes (Luft et al., 1979). ${ }^{26}$ Edward L. Hannan et al. (2003) estimate that inhospital mortality rates were significantly lower for hospitals with between 200 and 800

\footnotetext{
${ }^{25}$ We note, however, that we cannot reject the joint test for all entrant share groups that $\beta_{2}=\beta_{5}$ (p-value of .22). Despite this, the relative magnitudes of the coefficients for CABG- and PTCA-focused programs are consistent with our general model and suggest that entry by CABG-focused firms is more likely to lead to increased demand for high-quality inputs than is entry by PTCA-focused firms.

${ }^{26}$ See David M. Shahian and Sharon-Lise T. Normand (2003) and Gaynor et al. (2005) for discussions of the literature on the volume-outcome relationship.
} 
surgeries annually and for surgeons performing more than 125 surgeries annually (see Shahian and Normand (2003), Eric D. Peterson et al. (2004) and Ethan A. Halm et al. (2002) for additional discussion of appropriate volume thresholds). In this section, we use these cutoffs to distinguish high- and low-volume providers. Table 4 shows the share of hospitals and surgeons in our sample below recommended volume levels in different years. In 1994, 23 percent of hospitals and 65 percent of surgeons failed to meet these levels. In 2000, a year with approximately the same total CABG volume as 1994, these shares were higher for hospitals (27 percent) and lower for surgeons (60 percent). By 2003, the share of patients seen by below-threshold providers increased with respect to both hospitals and surgeons.

We are interested not simply in the share of hospitals and surgeons working at an efficient scale but also in the likelihood that a patient actually receives CABG from such a provider (i.e., one with annual volume above the threshold level). To address this issue we estimate a model of the following form:

$$
\ln \left(\frac{\text { highvol }_{i, h, t}}{1-\text { highvol }_{i, s, h, t}}\right)=\beta_{0}+\beta_{1} \text { entrantshare }_{j, t}+\beta_{2} Z_{i}+I_{t}+I_{j}+\varepsilon_{i, s, h, t}
$$

In (5), highvol $i, s, h$ is an indicator equal to one if patient $i$ received CABG from a highvolume surgeon, at a high-volume hospital, or from a high-volume surgeon-hospital pair (depending on the specification). Entrantshare $e_{j, t}$ is the share of volume in market $j$ in quarter $t$ going to hospitals that entered the market following the repeal of CON. $Z_{i}$ is a matrix of clinical and demographic characteristics for patient $i$ similar to that included in (1). In addition, we include quarter and market fixed effects and cluster standard errors at 
the market level. Given the binary dependent variable, we estimate (5) as a conditional logit model.

Column 1 of Table 5 presents estimates of the likelihood that a patient sees a high-volume surgeon. We define a high-volume surgeon according to several different thresholds for annual volume, ranging from 200 down to 75 cases per year. Column 2 repeats this analysis with respect to high-volume hospitals, again using multiple volume thresholds. Finally, Column 3 presents results based on threshold volumes for surgeonhospital pairings (i.e., the number of surgeries performed by a given surgeon at a specific hospital). This last specification is motivated by the potential for firm-specific volumeoutcome effects in cardiac surgery (Huckman and Gary P. Pisano, 2006). For each volume threshold, we present the coefficient estimate for $\beta_{1}$ in (5) as well as the marginal effect estimated at the patient-weighted-mean value of entrant share (19 percent).

The only statistically significant effects are found with respect to the likelihood that a patient is seen at a hospital performing in excess of 150 or 200 surgeries annually or that a patient is seen by a surgeon performing in excess of 100 surgeries annually. The hospital-level results suggest that a 10 percentage point increase in entrant share is associated with roughly a five percentage point reduction in the probability of CABG occurring at a hospital performing more than 200 CABGs in that year and a one percentage point reduction in the probability of CABG occurring at a hospital performing more than 150 procedures. These results, however, may reflect the fact that entrant hospitals are not operating at their equilibrium volumes shortly after entry. We also note that the same 10 percentage point increase in entrant share is associated with an 11 percentage point increase in the probability that CABG is provided by a surgeon 
performing at least 100 surgeries in that year. The estimates in Table 4 are sensitive to the choice of volume threshold. Given that fact, and the offsetting effects on physician and hospital volume, these results do not suggest a strong volume-related effect of entry on surgical quality.

\section{Changes in Travel Distance}

A final potential benefit of entry is reduced travel time for patients. Studies of consumer choice in health care consistently find that distance or travel time are important determinants of provider choice (Luft et al., 1990; Lawton R. Burns and Douglas R. Wholey, 1992; Mark McClellan et al., 1994; Michael E. Chernew et al., 1998). Travel time in medical care is particularly important in emergency settings, as longer travel can increase the probability of mortality. A large portion of CABGs, however, are elective. In the aftermath of a heart attack, a patient will be stabilized, and medications or PTCA will be used to open the blocked artery. CABG might be performed later - either during the initial admission or a subsequent one. For CABG, the issue of travel time is thus less one of survival than of convenience.

We address the impact of entry on travel distance by estimating the following equation:

$$
\text { dist }_{i, s, h, t}=\beta_{0}+\beta_{1} \text { entrantshare }_{j, t}+\beta_{2} Z_{i}+I_{t}+I_{j}+\varepsilon_{i, s, h, t}
$$


Dist $t_{i, s, h, t}$ is the distance (in miles) from the center of the patient's zip code to the center of the hospital's zip code. ${ }^{27}$ The estimate of $\beta_{1}$ is -0.12 (standard error $=.02$ ), which suggests that, at the mean entrant share, the average CABG recipient traveled 2.3 fewer miles following entry. This represents a nine percent reduction in travel distance relative to the patient-weighted average travel distance prior to entry of 27 miles. Nevertheless, for a one-time intervention lasting only a few days, such as CABG, this decrease may not have a large effect on consumer welfare. We return to this issue in the next section.

\section{THE WELFARE IMPACT OF FREE ENTRY}

Our results allow for a rough calculation of the gains and losses from free entry associated with the repeal of Pennsylvania's CON law. The cost of free entry is the fixed cost of the new programs. Estimates of the average fixed cost per new program vary between $\$ 12$ and \$14 million (Robinson et al., 2004; Huckman, 2006), yielding a total social cost of between $\$ 120$ million and \$280 million for the 10-to-20 new CABG programs we attribute to CON repeal. ${ }^{28}$

As noted above, a key benefit of entry is the improvement in quality as surgeries are transferred from standard- to high-quality surgeons. To estimate the number of deaths averted, we rely on coefficient estimates reported in Table 2. The average entrant share was 13 percent in 2000 and 19 percent in 2003 . We apply these entry shares to the coefficients in Table 2 to compute the additional share of surgeries done by high-quality

\footnotetext{
${ }^{27}$ Perhaps the best measure of distance is how far relatives and caregivers have to travel. Unfortunately, this information is not available.

${ }^{28}$ The lower bound is computed by comparing the number of new programs that entered in Pennsylvania in the five years between the repeal of CON and 2000 to the entry rate in New York and New Jersey (states that maintained CON) over the same period. During that period, an additional 12 programs entered in Pennsylvania compared to 3 in New York and 2 in New Jersey. We use the larger difference (10 programs) to ensure that our estimates are conservative. The upper bound assumes that all entry over our entire sample period (20 programs from 1995 to 2003) was due to the repeal of CON.
} 
surgeons following entry. Specifically, we compute the difference in average RAMR between the surgeons whose market share was increased (the top 10 percent), those who saw no change in volume (those in the $10^{\text {th }}$-to- $30^{\text {th }}$ percentiles), and those who would have otherwise performed the surgery (the bottom 70 percent of surgeons). Taking this change and scaling it by the average number of surgeries in Pennsylvania suggests that about 11 additional patients per year survived CABG because of the share redistribution following CON repeal.

The average Medicare beneficiary who survives bypass surgery lives another eight years. Assuming this applies to all CABG patients (54 percent are Medicare beneficiaries), the redistribution of volume across surgeons is associated with an increase of 88 life years for each calendar year. Quality of life during those years, however, is not perfect; Tammy O. Tengs and Amy Wallace (2000) estimate that patients receiving CABG who are still alive 10 years later have a quality of life of 0.9 on a scale of death (0) to perfect health (1). Thus, the above figure translates into 79 additional qualityadjusted life years (QALYs). ${ }^{29}$ The cost per QALY is therefore between $\$ 101,000$ and $\$ 236,000 .{ }^{30}$ Typical estimates of the value of a year of life in good health are between \$100,000 and \$250,000 (Cutler, 2004; Kevin M. Murphy and Robert H. Topel, 2006), a figure that is roughly equal to our estimate of the cost per QALY. ${ }^{31}$ Thus, our estimates

\footnotetext{
${ }^{29}$ A quality-adjusted life year (QALY) is a year of life in perfect health. We use the available QALY weight of 0.9 (Tengs and Wallace, 2000) for the patient population that most closely resembles that of interest in our study - patients receiving CABG who are alive 10 years after surgery.

${ }^{30}$ The fixed costs of entry are amortized over the lifespan of a new CABG operating room. Discussions with hospital executives suggest 15 years is an appropriate length of time.

31 The reduction in travel time also improves welfare but only by a small amount. Scaling the average reduction in travel distance ( 2.3 miles) by an estimate for the number of visitors and the median wage in Pennsylvania suggests a value of roughly $\$ 7.50$ per patient.
} 
suggest that gains from mortality reductions due to the redistribution of cases from standard- to high-quality surgeons approximately offset the fixed cost of free entry.

Our calculations involve several uncertainties. In addition to the issues noted above, we only account for quality improvements associated with in-hospital mortality. Entry and redistribution of volume may yield gains in patient outcomes other than mortality (e.g., reduced morbidity). Our calculations also do not account for the reduced cost associated with eliminating the administrative infrastructure required to operate Pennsylvania’s CON program. Finally, our estimates are based on attributing all of the fixed costs associated with a new CABG program to CABG alone when, in all likelihood, some portion of these costs should be attributed to a hospital's PTCA program (for which CABG represents a necessary backup) ${ }^{32}$ Given that all of these qualifications either lower the fixed costs attributable to CABG or increase the benefits of CABG entry, our cost-per-QALY estimates likely overestimate the true cost of CON repeal. With these caveats and given the range of welfare estimates, our results suggest on net that the repeal of CON was roughly welfare neutral.

\section{CONCLUSION}

The well-known potential for free entry to be inefficient is realized when firms make entry decisions without internalizing the costs associated with the business they "steal” from incumbent firms. We show that input scarcity materially affects this conclusion. Theoretically, adding firms to a market with input scarcity is less likely to lead to excessive entry because entry is both inherently limited by factor supply and likely to increase demand differentially for high-quality factors of production. 
In the setting we consider - the entry of CABG programs in Pennsylvania - this quality effect is apparent. Market share is distributed to higher-quality surgeons following entry, thereby improving the overall quality of surgical outcomes. The resulting welfare gains from entry are about equal to the losses from increased fixed costs, making free entry approximately welfare neutral.

Our setting is specific in at least three ways. First, the technology we consider is relatively mature. It is possible that the volume-outcome effects associated with transferring volume in settings with more nascent technologies—which are not toward the "flat" of the learning curve-might have different effects (either positive or negative) on welfare. In addition, we lack information on the impact of entry on price. While the lack of price information does not pose an obstacle for our analysis — due to the presence of a significant amount of administered pricing for CABG — changes in price may play a more meaningful role in welfare calculations in other settings. Finally, our study period coincides with the introduction of quality reporting for CABG in Pennsylvania (David Dranove, et al., 2003). We do not feel that the presence of these public reports should bias our findings, as reporting occurred simultaneously across the entire state while our empirical identification exploits the fact that different markets experienced varying levels and timing of entry. If, however, reporting facilitated the differentiation of inputs (e.g.. without quality reporting high quality surgeons could not be identified by hospitals), the effects of entry we observe may be more muted in markets with less information on quality.

Even with these limitations, we suspect that the pattern underlying our results may be general. Many professions rely on highly- and variably-skilled individuals. 
Consider, for example, a new firm looking to enter investment banking. In addition to setting up a physical facility, the firm needs to hire or contract with specialized labor (i.e., investment bankers). In the short term, the supply of these factors is relatively inelastic. Even in manufacturing — where the supply of production workers may be more elasticindustry-specific managerial talent may be specialized, and land of appropriate quality may be in fixed supply. As such, examining the welfare implications of entry in other markets represents a natural avenue for future research. 


\section{References}

Abraham, Jean M., Martin S. Gaynor, and William B. Vogt. Forthcoming. "Entry and Competition in Local Hospital Markets.” Journal of Industrial Economics.

Arrow, Kenneth. 1963. "Uncertainty and the Welfare Economics of Medical Care.” American Economic Review , 53(3): 941-73.

Berry, Steven T. and Joel Waldfogel.1999. "Free Entry and Social Inefficiency in Radio Broadcasting.” RAND Journal of Economics, 30(3): 397-420.

Bresnahan, Timothy F. and Peter C. Reiss. 1991. "Entry and Competition in Concentrated Markets.” Journal of Political Economy, 99(3): 977-1009.

Burns, Lawton R., and Douglas R. Wholey. 1992. “The Impact of Physician Characteristics in Conditional Choice Models for Hospitals.” Journal of Health Economics, 11 (1), 43-62.

Chernew, Michael E., Dennis Scanlon and Rod Hayward. 1998. "Insurance Type and Choice of Hospital for Coronary Artery Bypass Graft Surgery.” Health Services Research, 33 (3), 447-466.

Chernew, Michael E., Gautam Gowrisankaran, and A. Mark Fendrick. 2002. "Payer Type and the Returns to Bypass Surgery: Evidence from Hospital Entry Behavior.” Journal of Health Economics, 21(3), 451-474.

Conover, Christopher J. and Frank A. Sloan. 1998. “Does Removing Certificate-of-Need Regulations Lead to a Surge in Health Care Spending?” Journal of Health Politics, Policy and Law, 23(3): 455-481.

Cutler, David M. 2004. Your Money or Your Life: Strong Medicine for America's Health Care System. Oxford University Press. Oxford, UK.

Cutler, David M. and Robert S. Huckman. 2003. “Technology Development and Medical Productivity: The Diffusion of Angioplasty in New York State.” Journal of Health Economics, 22(2): 187-217

DiSesa, Verdi J., Sean M. O’Brien, Karl F. Welke, Sarah M. Beland, Constance K. Haan, Mary S. Vaughan-Sarrazin, and Eric D. Peterson. 2006. “Contemporary Impact of State Certificate-of-Need Regulations for Cardiac Surgery: An Analysis Using the Society of Thoracic Surgeons’ National Cardiac Surgery Database.” Circulation, 114(20): 2122-2129. 
Dixit, Avinash K. and Joseph E. Stiglitz. 1977. "Monopolistic Competition and Optimal Product Diversity.” American Economic Review, 67(3): 297-308.

Dranove, David, Daniel Kessler, Mark McClellan, and Mark Satterthwaite. (2003). "Is More Information Better? The Effect of "Report Cards” on Health Care Providers.” Journal of Political Economy, 111(3), 555-588.

Gaynor, Martin. 2006. "What Do We Know About Competition and Quality in Health Care Markets?” NBER Working Paper 12301.

Gaynor, Martin, Harald Seider, and William B.Vogt. 2005. “The Volume-Outcome Effect, Scale Economies and Learning-by-Doing.” American Economic Review, 95(2): 243-247.

Halm, Ethan A., Clara Lee, and Mark R. Chassin. 2002. “Is Volume Related to Outcome in Health Care? A Systematic Review and Methodological Critique of the Literature.” Annals of Internal Medicine, 137(6), 511-520.

Hannan, Edward L., Chuntao Wu, Thomas J. Ryan, Edward Bennett, Alfred T. Culliford, Jeffrey P. Gold, Alan Hartman, O. Wayne Isom, Robert H. Jones, Barbara McNeil, Eric A. Rose, and Valvanur A. Subramanian. 2003. "Do Hospitals and Surgeons with Higher Coronary Artery Bypass Graft Surgery Volumes Still Have Lower RiskAdjusted Mortality Rates?” Circulation, 108(5): 795-801.

Hart, Oliver and Jean Tirole. 1990. "Vertical Integration and Market Foreclosure.” Brookings Papers on Economic Activity (Microeconomics). 1990, 205-208.

Ho, Vivian. 2006. “Does Certificate of Need Affect Cardiac Outcomes and Costs?” International Journal of Healthcare Finance and Economics, 6(4): 300-324.

Huckman, Robert S. 2006 "Hospital Integration and Vertical Consolidation: An Analysis of Acquisitions in New York State.” Journal of Health Economics, 25(1): 58-80.

Huckman, Robert S. and Gary P. Pisano. 2006. “The Firm Specificity of Individual Performance: Evidence from Cardiac Surgery”. Management Science, 52(4): 473-488.

Jones, Robert H. 2006. “Does Government Regulation Enhance Quality of Cardiovascular Procedures?” Circulation, 114(20): 2090-2091.

Mankiw, N. Gregory and Whinston, Michael D. 1986. "Free Entry and Social Inefficiency.” RAND Journal of Economics, 77(3): 48-58. 
Koenker, Roger W. and Martin K. Perry. 1981. "Product Differentiation, Monopolistic Competition, and Public Policy.” Bell Journal of Economics, 12(1): 217-231.

Luft, Harold S., John P. Bunker, and Alain C. Enthoven, A. 1979. “Should Operations be Regionalized? The Empirical Relation Between Surgical Volume and Mortality.” New England Journal of Medicine. 301(25): 1364-1369.

Luft, Harold S., Deborah W. Garnick, David H. Mark, Deborah J. Peltzman, Ciaran S. Phibbs, Erik Lichtenber, and Stephen J. McPhee.1990. “Does Quality Influence Choice of Hospital?” Journal of the American Medical Association, 263 (21): 2899-906.

McClellan, Mark, Barbara J. McNeil, and Joseph P. Newhouse. 1994. "Does More Intensive Treatment of Acute Myocardial Infarction in the Elderly Reduce Mortality? Analysis Using Instrumental Variables.” Journal of the American Medical Association. 272(11), 859-866.

Murphy, Kevin M. and Robert H. Topel. 2006. “The Value of Health and Longevity” Journal of Political Economy. 114(5), 871-904.

National Center for Health Statistics. 2006. "Trends in Health and Aging,” http://209.217.72.34/aging/ReportFolders/reportFolders.aspx, accessed August 15, 2006.

Newhouse, Joseph P. 1970 "Toward a Theory of Nonprofit Institutions: An Economic Model of a Hospital.” American Economic Review, 60(1): 65-71.

Pauly, Mark V. 2004 “Competition in Medical Services and the Quality of Care: Concepts and History.” International Journal of Health Care Finance and Economics, 4(2): 113-130.

Pennsylvania Health Care Cost Containment Council. 1998. Coronary Artery Bypass Graft Surgery-1994-95 Data: Research Methods and Results.

Pennsylvania Health Care Cost Containment Council. 2002. Coronary Artery Bypass Graft Surgery-2000 Data: Research Methods and Results.

Pennsylvania Health Care Cost Containment Council. 2004. Coronary Artery Bypass Graft Surgery-2002 Data: Technical Notes.

Pennsylvania Health Care Cost Containment Council. 2005. Coronary Artery Bypass Graft Surgery—2003 Data: Technical Notes. 
Peterson, Eric D., Laura P. Coombs, Elizabeth R. DeLong, Constance K. Haan, and T.

Bruce Ferguson. 2004. "Procedural Volume as a Marker of Quality for CABG

Surgery.” Journal of the American Medical Association, 291(2):195-201.

Rey, Patrick and Jean Tirole. 2007. In The Handbook of Industrial Organization Volume

3. Eds. Mark Armstrong and Robert H. Porter. Amsterdam: Elsivier

Robinson, James C. and Harold S. Luft. 1987. “Competition and Cost of Hospital Care 1972-1982.” Journal of the American Medical Association, 257(23):3241-3245.

Robinson, Jamie L, David B Nash, Elizabeth Moxey, and John P. OConnor. 2001.

“Certificate of Need and the Quality of Cardiac Surgery.” American Journal of Medical Quality, 16(3):155-160.

Shahian, David M., and Sharon-Lise T. Normand, 2003. "The volume-outcome relationship: from Luft to Leapfrog.” Annals of Thoracic Surgery, 75(3): 1048-1058.

Spence, A. Michael. 1980. "Product Selection, Fixed Costs, and Monopolistic Competition.” Review of Economic Studies, 43(2): 217-235.

Sutton, John. Sunk Cost and Market Structure. Cambridge, MA: MIT Press. 1991.

Tengs, Tammy O., and Amy Wallace. 2000. “One Thousand Health-Related Quality-ofLife Estimates.” Medical Care, 38(4): 583-637.

Wennberg, John E., Megan M. Cooper, and Dartmouth Atlas of Health Care Working Group. 1999. The Dartmouth Atlas of Health Care 1999. Chicago: American Hospital Publishing.

Zeckhauser, Richard. 1970. "Medical Insurance: A Case Study of the Tradeoff Between Risk Spreading and Appropriate Incentives,” Journal of Economic Theory, 2(1): 10-26. 
Table 1: Description of Incumbent and Entrant CABG Programs in Pennsylvania

\begin{tabular}{|c|c|c|c|c|c|c|}
\hline & $\begin{array}{c}\text { Number } \\
\text { of } \\
\text { Programs }\end{array}$ & $\begin{array}{c}\text { Annual } \\
\text { CABGs }\end{array}$ & $\begin{array}{c}\text { Average } \\
\text { Surgeons* }\end{array}$ & $\begin{array}{c}\text { Average } \\
\text { Surgeons } \\
\text { per } \\
\text { Program }\end{array}$ & $\begin{array}{c}\text { Annual } \\
\text { CABGs per } \\
\text { Surgeon** }\end{array}$ & $\begin{array}{c}\text { Average } \\
\text { Hospital } \\
\text { RAMR }\end{array}$ \\
\hline $\begin{array}{l}\text { Incumbent Programs } \\
\text { 1994-1995 }\end{array}$ & 43 & 451 & 203 & 4.72 & 95 & $3.10 \%$ \\
$\mathbf{2 0 0 0 , 2 0 0 2 - 2 0 0 3}$ & 40 & 349 & 201 & 5.03 & 96 & $2.17 \%$ \\
\hline $\begin{array}{c}\text { Entrant Programs } \\
\text { 2000, 2002-2003 }\end{array}$ & 23 & 160 & 115 & 4.79 & 87 & $2.04 \%$ \\
\hline
\end{tabular}

*Figures include all individuals practicing at a given program type and, thus, may count a surgeon twice if he or she splits time across incumbent and entrant programs.

** Average total number of procedures across all hospitals by surgeons practicing at incumbent and entrant hospitals in each period.

Source: PHC4 CABG Database

Table 2: Impact of Entrant Share on the Share of CABG Procedures by Standardand High-Quality Surgeons

\begin{tabular}{|c|c|c|c|c|}
\hline \multicolumn{5}{|c|}{ urgeon Market Share } \\
\hline \multirow{2}{*}{\multicolumn{5}{|c|}{$\beta_{1}:$ Entrant Share Group }} \\
\hline & & & & \\
\hline $1-10 \%$ & $-0.009(0.003) * *$ & $-0.008(0.004) * *$ & $-0.008(0.004) * \star$ & $-0.005(0.004)$ \\
\hline $11-20 \%$ & $-0.012(0.007) *$ & $-0.009(0.008)$ & $-0.011(0.008)$ & $-0.006(0.007)$ \\
\hline $20 \%+$ & $-0.014(0.008)$ * & $-0.008(0.008)$ & $-0.010(0.008)$ & $-0.004(0.007)$ \\
\hline \multicolumn{5}{|c|}{$\beta_{2}:$ Entrant Share Group * High-Quality Surgeon } \\
\hline $1-10 \%$ & $0.026(0.010) * *$ & $0.014(0.008)$ * & $0.013(0.007)$ * & $0.004(0.007)$ \\
\hline $11-20 \%$ & $0.021(0.010)$ ** & 0.007 (0.009) & $0.009(0.010)$ & $-0.002(0.010)$ \\
\hline $20 \%+$ & $0.020(0.013)$ & $-0.005(0.010)$ & $0.005(0.010)$ & $-0.008(0.010)$ \\
\hline \multicolumn{5}{|c|}{$\beta_{3}:$ Entrant Share Group * New Surgeon } \\
\hline $1-10 \%$ & $0.008(0.005)$ & $0.007(0.006)$ & $0.007(0.006)$ & $0.004(0.006)$ \\
\hline $11-20 \%$ & $0.018(0.011)$ & $0.015(0.012)$ & $0.016(0.012)$ & $0.011(0.011)$ \\
\hline $20 \%+$ & $0.019(0.012)$ & $0.013(0.013)$ & $0.016(0.013)$ & $0.010(0.012)$ \\
\hline Year $=2002$ & $-0.002(0.002)$ & $-0.002(0.002)$ & $-0.002(0.002)$ & $-0.002(0.002)$ \\
\hline Year $=2003$ & $0.000(0.002)$ & $0.000(0.002)$ & $0.000(0.002)$ & $0.000(0.002)$ \\
\hline Observations & 3,836 & 3,836 & 3,836 & 3,836 \\
\hline R-Squared & 0.8961 & 0.8961 & 0.8958 & 0.8958 \\
\hline
\end{tabular}

Note: $* * *, * * *$ denote statistical significance at the $10 \%, 5 \%$ and $1 \%$ level, respectively. Includes observations only for the years following the repeal of CON in Pennsylvania (i.e., 2000, 2002, and 2003). All models include surgeon-market fixed effects. Standard errors (in parentheses) are clustered by surgeon and market. 
Table 3: Impact of Entrant Share on the Share of CABG Procedures Standard- and High-Quality Surgeons Differentiated by Entering Hospital Focus (PTCA vs. CABG)

\begin{tabular}{|c|c|c|c|c|}
\hline \multicolumn{5}{|c|}{ pendent Variable: Surgeon Market Share } \\
\hline \multirow{2}{*}{\multicolumn{5}{|c|}{$\beta_{1}:$ CABG Focused Entrant Share Group }} \\
\hline & & & & \\
\hline $1-10 \%$ & $-0.009(0.005) * *$ & $-0.008(0.006)$ & $-0.008(0.006)$ & $-0.002(0.007)$ \\
\hline $11-20 \%$ & $-0.011(0.007)$ & $-0.007(0.008)$ & $-0.007(0.008)$ & $0.000(0.006)$ \\
\hline $20 \%+$ & $-0.008(0.006)$ & $-0.004(0.007)$ & $-0.004(0.007)$ & $0.003(0.009)$ \\
\hline \multicolumn{5}{|c|}{$\beta_{2}:$ CABG Focused Entrant Share Group * High-Quality Surgeon } \\
\hline $1-10 \%$ & $0.027(0.011)$ ** & $0.013(0.009)$ & $0.012(0.009)$ & $0.003(0.009)$ \\
\hline $11-20 \%$ & $0.020(0.011) *$ & $0.007(0.011)$ & $0.007(0.011)$ & $-0.004(0.011)$ \\
\hline $20 \%+$ & $0.031(0.015) * \star$ & $0.009(0.011)$ & $0.008(0.010)$ & $0.000(0.010)$ \\
\hline \multicolumn{5}{|c|}{$\beta_{3}:$ CABG Focused Entrant Share Group * New Surgeon } \\
\hline $1-10 \%$ & $0.018(0.007)$ ** & $0.017(0.008) * \star$ & $0.016(0.008) * *$ & $0.013(0.008)$ \\
\hline $11-20 \%$ & $0.022(0.011) *$ & $0.018(0.012)$ & $0.018(0.012)$ & $0.013(0.011)$ \\
\hline $20 \%+$ & $0.022(0.010) * \star$ & $0.018(0.011)$ * & $0.018(0.011)$ & $0.014(0.010)$ \\
\hline \multicolumn{5}{|c|}{$\beta_{4}:$ PTCA Focused Entrant Share Group } \\
\hline $1-10 \%$ & $-0.001(0.002)$ & $-0.001(0.002)$ & $0.000(0.002)$ & $-0.001(0.002)$ \\
\hline $11-20 \%$ & $-0.002(0.011)$ & $-0.002(0.012)$ & $-0.001(0.012)$ & $-0.002(0.013)$ \\
\hline $20 \%+$ & $-0.011(0.016)$ & $-0.011(0.016)$ & $-0.010(0.016)$ & $-0.016(0.019)$ \\
\hline \multicolumn{5}{|c|}{$\beta_{5}:$ PTCA Focused Entrant Share Group * High-Quality Surgeon } \\
\hline $1-10 \%$ & $0.001(0.005)$ & $0.001(0.004)$ & $-0.001(0.004)$ & $-0.001(0.004)$ \\
\hline $11-20 \%$ & $0.006(0.012)$ & $0.003(0.013)$ & $0.002(0.013)$ & $0.003(0.013)$ \\
\hline $20 \%+$ & $0.015(0.016)$ & $0.015(0.016)$ & $0.013(0.016)$ & $0.021(0.020)$ \\
\hline \multicolumn{5}{|c|}{$\beta_{6}:$ PTCA Focused Entrant Share Group * New Surgeon } \\
\hline $1-10 \%$ & $-0.005(0.004)$ & $-0.006(0.004)$ & $-0.006(0.004)$ & $-0.006(0.004)$ \\
\hline $11-20 \%$ & $-0.009(0.020)$ & $-0.009(0.021)$ & $-0.009(0.021)$ & $-0.008(0.021)$ \\
\hline $20 \%+$ & $0.022(0.020)$ & $0.021(0.020)$ & $0.021(0.020)$ & $0.027(0.023)$ \\
\hline Year $=2002$ & $-0.003(0.002) *$ & $-0.003(0.002)$ * & $-0.003(0.002)$ * & $-0.003(0.002)$ * \\
\hline Year $=2003$ & $-0.002(0.002)$ & $-0.002(0.002)$ & $-0.002(0.002)$ & $-0.002(0.002)$ \\
\hline Observations & 3,836 & 3,836 & 3,836 & 3,836 \\
\hline R-Squared & 0.8664 & 0.8957 & 0.8957 & 0.8655 \\
\hline
\end{tabular}

*,**, and ${ }^{* \star \star}$ denote statistical signficance at the $10 \%, 5 \%$, and $1 \%$ levels, respectively. 
Table 4: Hospitals and Surgeon Operating Below Selected Volume Thresholds

\begin{tabular}{|l|c|c|c|c|c|}
\hline & $\mathbf{1 9 9 4}$ & $\mathbf{1 9 9 5}$ & $\mathbf{2 0 0 0}$ & $\mathbf{2 0 0 2}$ & $\mathbf{2 0 0 3}$ \\
\hline Hospitals wl Annual Volume <200 & 10 & 7 & 15 & 27 & 29 \\
\hline Total Hospitals & 43 & 43 & 55 & 62 & 63 \\
\hline Share Below Threshold & $23 \%$ & $16 \%$ & $27 \%$ & $44 \%$ & $46 \%$ \\
\hline \multicolumn{5}{|l|}{} \\
\hline Surgeons wl Annual Volume <125 & 120 & 114 & 109 & 146 & 147 \\
\hline Total Surgeons & 184 & 189 & 182 & 188 & 182 \\
\hline Share Below Threshold & $65 \%$ & $60 \%$ & $60 \%$ & $78 \%$ & $81 \%$ \\
\hline
\end{tabular}

Source: PHC4 CABG database

Table 5: Impact of New Entrant Share on the Likelihood of Seeing an AboveThreshold Provider

\begin{tabular}{|c|c|c|c|}
\hline Dependent Variable: & $\begin{array}{c}\text { Surgeon Volume } \\
\text { Above Threshold? }\end{array}$ & $\begin{array}{c}\text { Hospital Volume } \\
\text { Above Threshold? }\end{array}$ & $\begin{array}{c}\text { Surgeon-Hospital } \\
\text { Volume Above } \\
\text { Threshold? }\end{array}$ \\
\hline & Threshold=200 & Threshold=300 & Threshold=200 \\
\hline$\beta_{1}$ : Entrant Share & $-0.002 \quad(0.068)$ & $-0.018(0.022)$ & $0.072(0.082)$ \\
\hline \multirow[t]{2}{*}{ Marginal Effect } & $0.000(0.002)$ & $-0.004(0.005)$ & $0.002(0.002)$ \\
\hline & Threshold=150 & Threshold=200 & Threshold=150 \\
\hline$\beta_{1}$ : Entrant Share & $0.013 \quad(0.029)$ & $-0.049(0.025)$ ** & $0.026 \quad(0.029)$ \\
\hline \multirow[t]{2}{*}{ Marginal Effect } & $0.002(0.005)$ & $-0.005(0.002) * *$ & $0.004 \quad(0.004)$ \\
\hline & Threshold=125 & Threshold=150 & Threshold=125 \\
\hline$\beta_{1}:$ Entrant Share & $0.031 \quad(0.024)$ & $-0.054(0.023)$ ** & $0.011(0.025)$ \\
\hline Marginal Effect & $0.008(0.006)$ & $-0.001(0.001) * *$ & $0.003(0.006)$ \\
\hline & Threshold=100 & Threshold=100 & Threshold=100 \\
\hline$\beta_{1}$ : Entrant Share & $0.050(0.021)$ ** & $0.000(0.043)$ & $0.016(0.015)$ \\
\hline \multirow[t]{2}{*}{ Marginal Effect } & $0.011(0.005)$ ** & $0.000(0.000)$ & $0.004 \quad(0.004)$ \\
\hline & Threshold=75 & Threshold=75 & Threshold $=75$ \\
\hline$\beta_{1}:$ Entrant Share & $0.000(0.020)$ & $-0.019(0.060)$ & $0.004 \quad(0.013)$ \\
\hline Marginal Effect & $0.000(0.002)$ & $0.000(0.000)$ & $0.001 \quad(0.002)$ \\
\hline Observations & 37,708 & 37,708 & 37,708 \\
\hline
\end{tabular}

Note: $*, * *, * * *$ denote statistical significance at the $10 \%, 5 \%$ and $1 \%$ level, respectively. Includes observations only for the years following the repeal of CON in Pennsylvania (i.e., 2000, 2002, and 2003). The following variables are included in the regression but are not shown in the table: age, age ${ }^{2}$, calendar quarter fixed effects, market fixed effects, indicators for cardiogenic shock, concurrent angioplasty, complicated hypertension, dialysis, female gender, heart failure, and prior CABG or valve surgery. Standard errors (in parentheses) are clustered by market. 
Figure 1: Number and Market Share of Entrant Programs

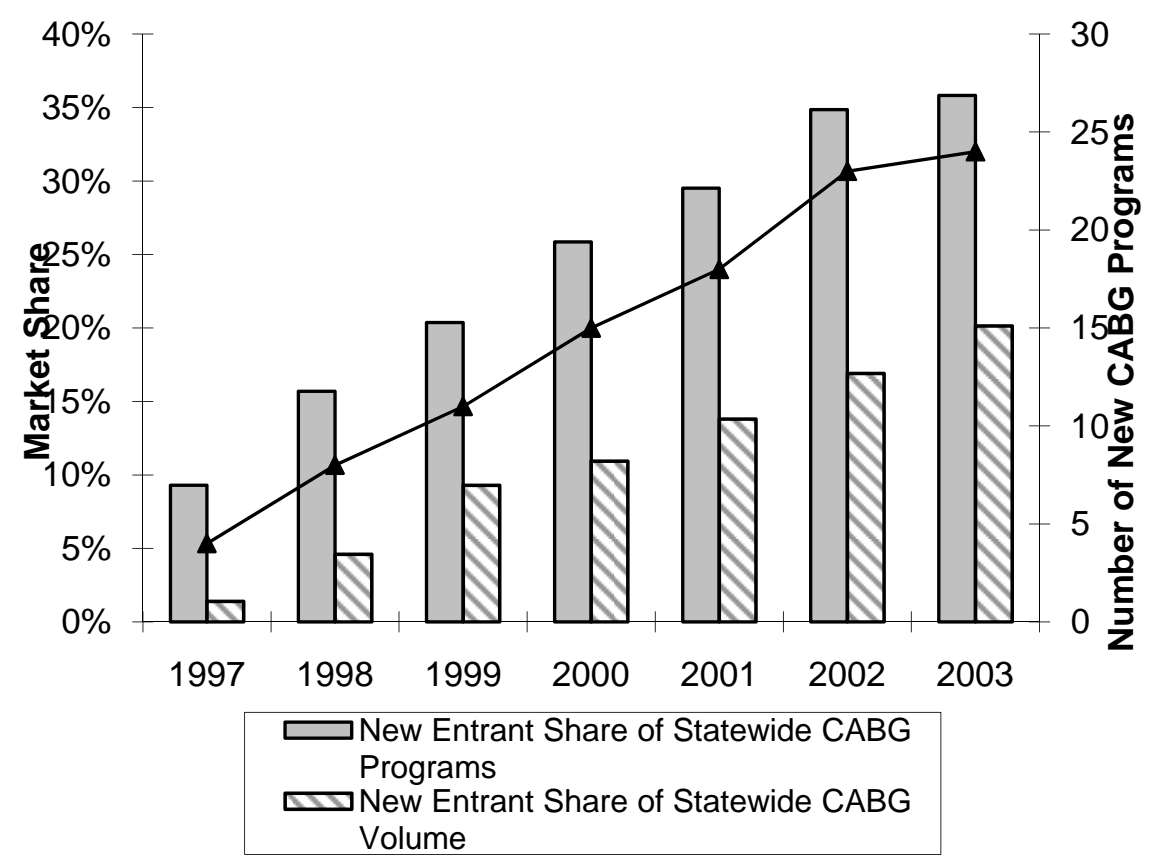

Source: PHC4 Hospital Discharge Database

Figure 2: Total CABG Programs in Pennsylvania, New York and New Jersey

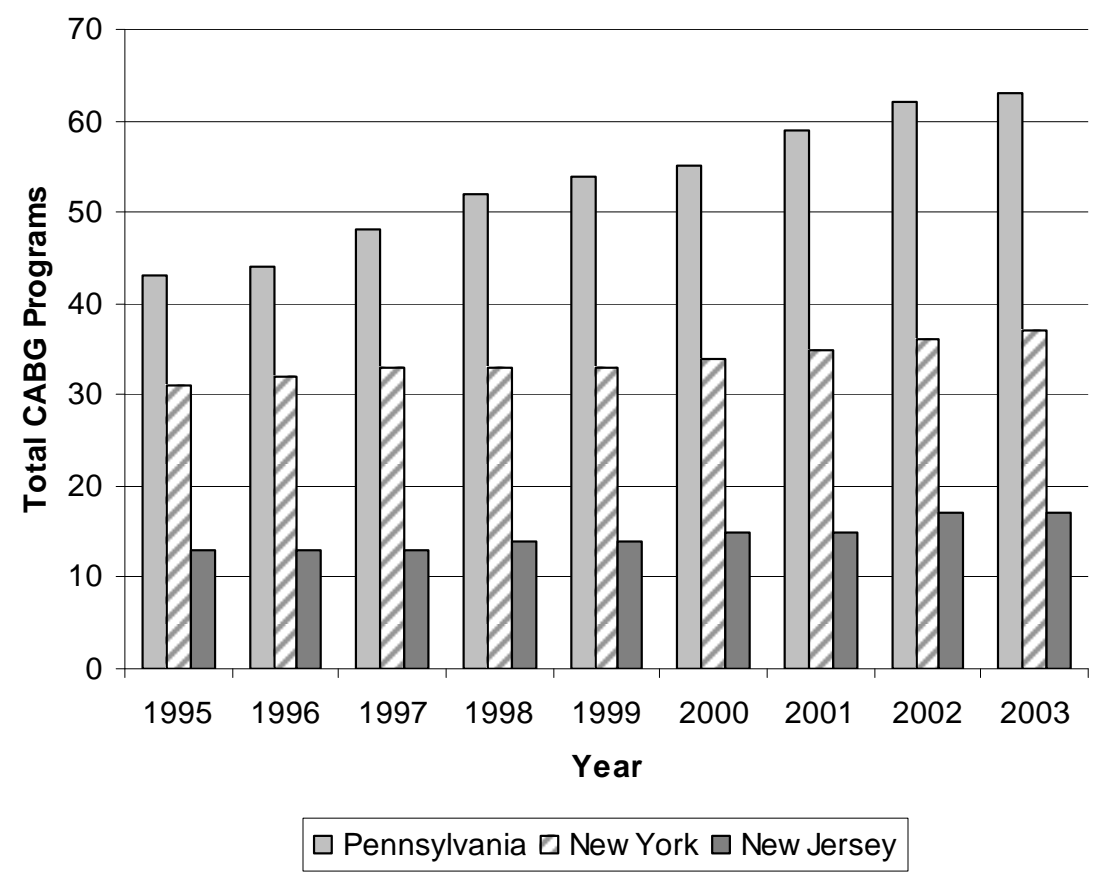

Source: PHC4, New York State Department of Health, New Jersey Department of Health and Senior Services. 
Figure 3: Map of Incumbent and Entrant CABG Hospitals in Pennsylvania

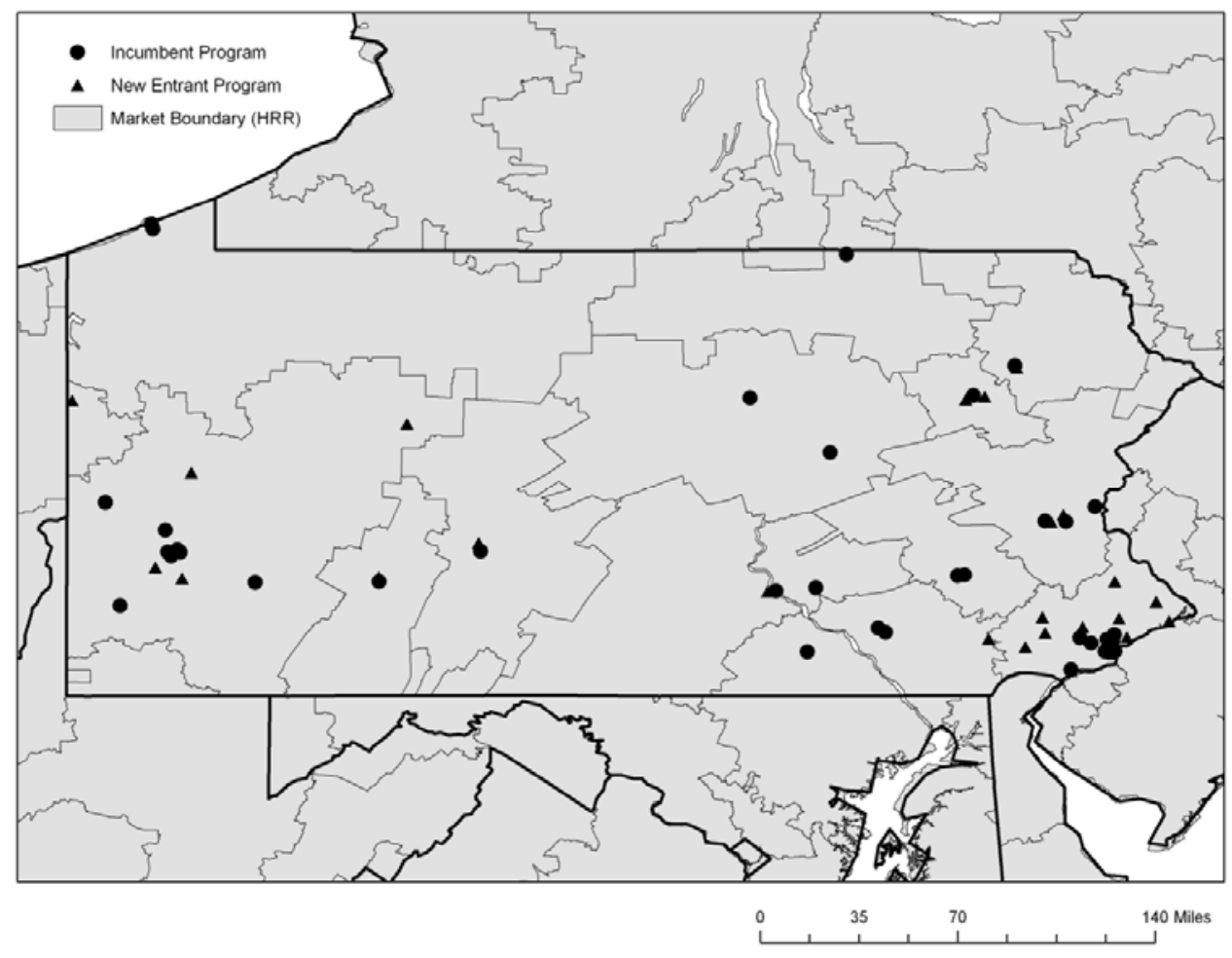


Figure 4: Per Capita CABG Utilization in Pennsylvania, New York and New Jersey

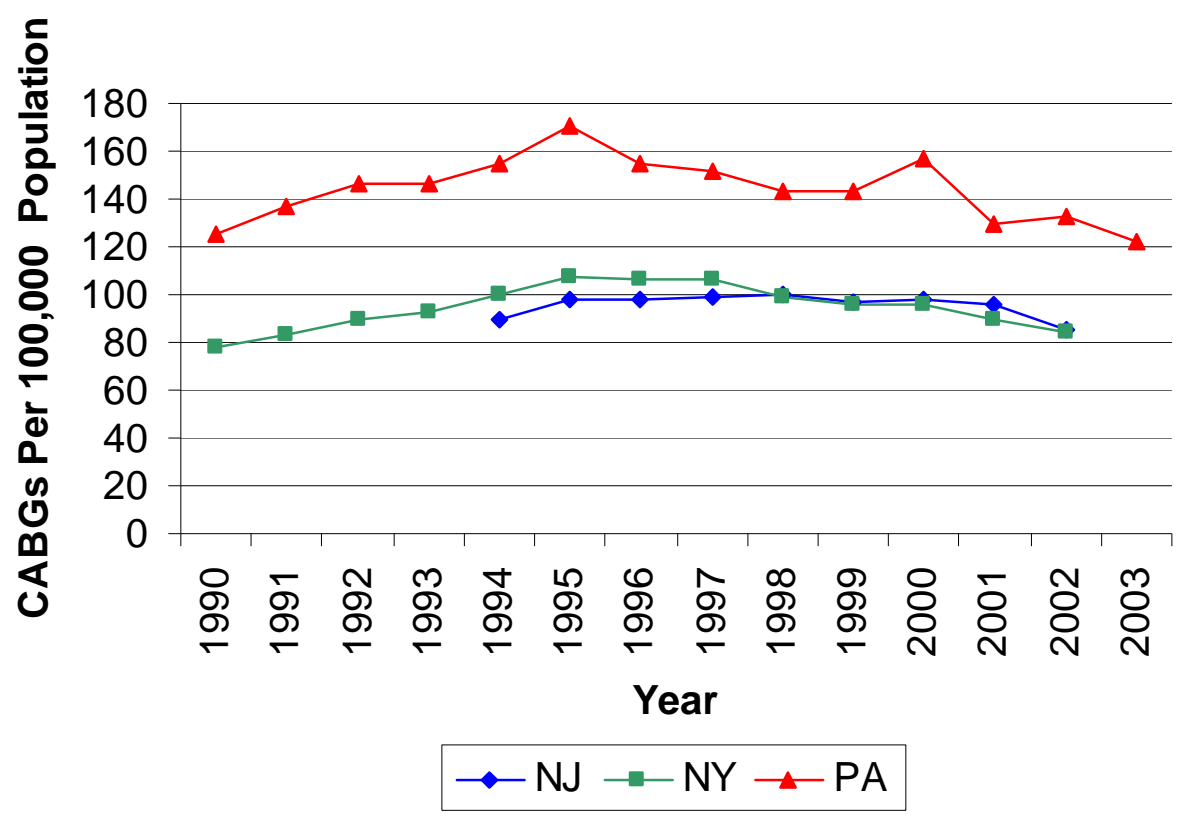

Source: PHC4, New York State Department of Health, New Jersey Department of Health and Senior Services, and U.S. Census Bureau

Figure 5: Operating Margin by Entry Status for Pennsylvania Hospitals

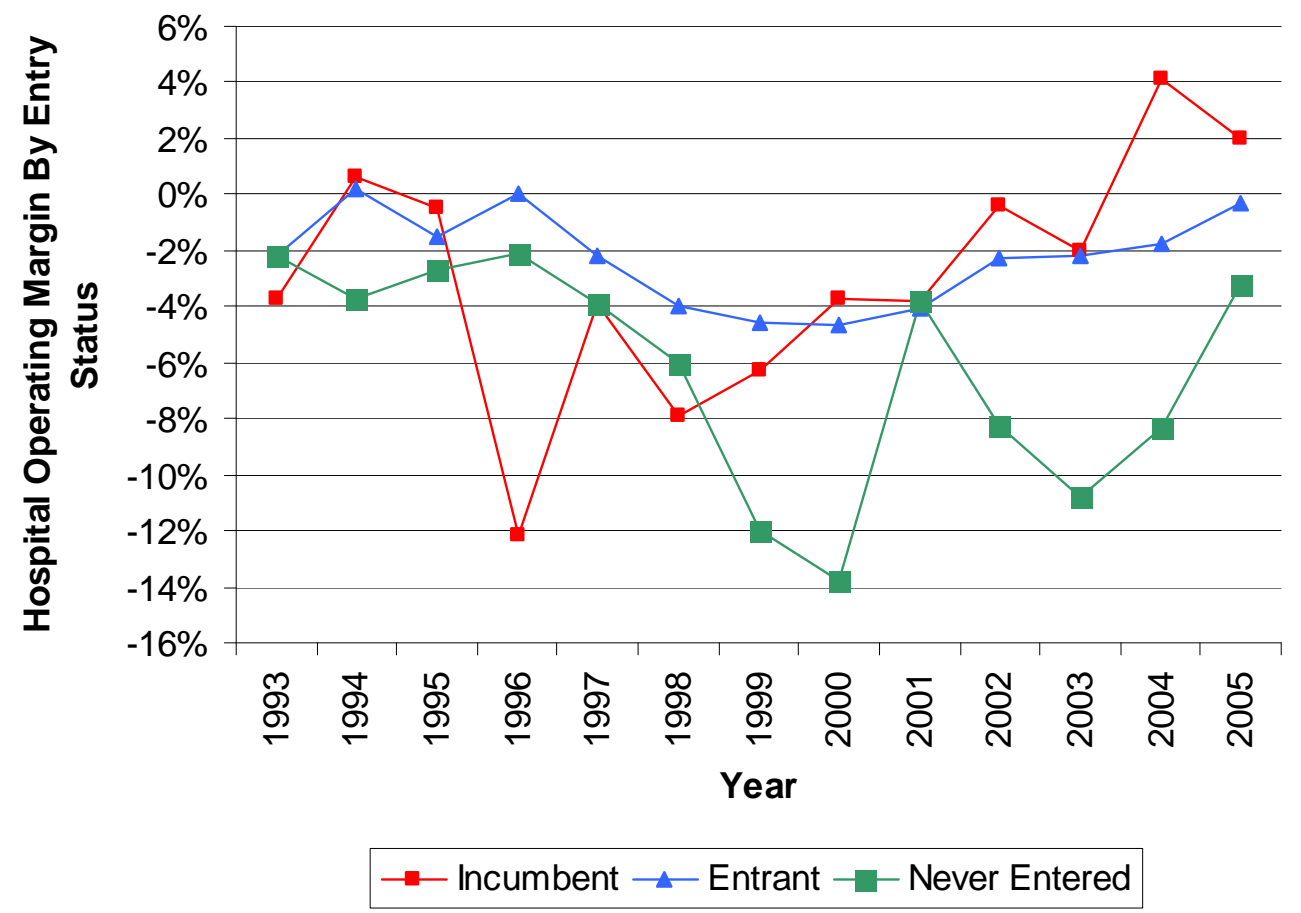

Source: Medicare Cost Reports 